\title{
Links Between Work, Character, and Education. The Actuality of Erich Fromm's Analytical Social Psychology
}

\author{
Burkhard Bierhoff ${ }^{*}$ \\ ${ }^{1}$ Hochschule Lausitz - University of Applied Sciences, Fachbereich Sozialwesen, 47 Lipezker Str., 03048 Cottbus, Germany
}

KEYWORDS

Analytical social

psychology

Education

Social change

Social character

Unconditional basic

income

Work
ABSTRACT

This article reveals the basic ideas of Erich Fromm's analytical social psychology and shows links among work, character and education. Social changes may be better understood in the background of work evolution. Today the concept of waged work has been extended to unpaid activities. At the same time, the working life has been changed from a stable model to a flexible one. The work, its standards and social distribution, are also different now. Erich Fromm's concept of 'social character' clarifies the changes and explains the consequences of the social changes. The relations to work are also different. During these changes - unemployment included - concepts of the unconditional basic income were studied. These concepts explain why it's possible for people without waged work to participate in community life and consumption, without being excluded. The author presents the basic social changes that affected many different subpopulation and age groups.

\section{Introduction}

Erich Fromm created the analytical social psychology, which was based on Freudian psychoanalysis and materialistic philosophy. As a former member of the Frankfurt school of critical theory, Fromm dealt with the questions related to social theory and subject theory for almost fifty years. The concept of 'social character' and its contribution to the sociology of work were of much interest to Fromm. This essay recalls Erich Fromm's contribution toward a humanistic science. Within the Frommian frame of reference, the

\footnotetext{
${ }^{*}$ Contact address: burkhard.bierhoff@hs-lausitz.de (B. Bierhoff).
} 
article explores the relationship among work, character and education. A forecast of the possible consequences and processes of change with an evaluation of social change is attempted.

We are currently in the process of profound social changes. Traditional certainties and forms of life are questioned or they disappeared. The lack of transparency, which can be found in social structures and uncertain living conditions lead to irksome uncertainties. The employment sector with its premises of economic growth has reached the bounds of ecological reasonability. The socializing and disciplining function of waged work seems to decrease still further with the much attested 'end of the employment society'.

Within the last three decades, the work in post-industrial societies has changed considerably. This changing process in the structures of the work organization and in people's work activity is roughly outlined here.

Until the 1980s, a model of work characterized by full employment with job security was widespread. This has disappeared now. Today unemployment is increasing and we face to other related changes (reduced hours, precarious employment relations - wage dumping, temporary employment). It can be noticed that the social understanding and the social valuation of work have changed. The model of work stability has changed to a model of work flexibility. During this change, the workers' demands have been radicalized (flexible locations and hours, reduced pay and social security). Working people must become more and more flexible (Sennett 1998).

In the context of this socially accepted model, there is a close connection between wage labour and consumption, or rather, the opportunity for consumption. The people who work and earn money have the right to a 'good' life in consumer society. If work becomes 'scarce', people are forced to forego consumption. Particularly in precarious employment relations, this has effects on lifestyle and attitude toward life, including diminished self-esteem.

In the industrial work model, the material pressure of living conditions led to a complete disciplining of the working people. Karl Marx emphasized not only the alienating nature of work, tied to its exploitative nature, but he moved work to the centre of human activity and saw it as a 
basis for self-realization (Fromm 1961: 40). Erich Fromm drew into his own social perspective the particularities of the working and consuming person related to the socioeconomic base.

Industrial society was characterized by a vast and comprehensive alienation of workers. Socially regulated and organized working conditions made it possible to pay labour as a socially accepted work form. The criticism of pauperization and exploitation of the worker was based on the idea that all people should be able to develop their personalities through their work.

Even though waged work, particularly in factories, had little to do with a person's self-realization, work as the basis for a person's selfrealization was one of the ideals and ideological keystones in the employment society.

The paid worker had to become disciplined for producing. He had to be punctual and complete his assigned tasks without protest. He had to follow instructions and be obedient. In return, he was granted a wage that was only sufficient to reproduce and restore his working possibilities. Nourishing the family was a question of survival and hinged upon the early cooperation of family members.

With the social welfare legislation in Germany, enacted in 1883, the consequences of inhumane working conditions were limited and a system of social security was introduced and retained unchanged far into the $20^{\text {th }}$ century.

At the time of full employment at the beginning of the second half of the $20^{\text {th }}$ century, social security, economic prosperity and upward mobility were guaranteed by the increased consumption opportunities and the acquisition of goods that were still regarded as luxury ones, a short time before. Working relationships were stable throughout this time period and characterized by full-time employment. They were unlimited and linked to rising incomes. Unemployment was rather the exception. Expectations of mobility and flexibility were almost non-existent. Through paid work, social participation and integration of the population's majority were guaranteed.

Until far into the second half of the $20^{\text {th }}$ century, social integration of the population majority took place through gainful employment in paid working conditions. At the end of the $20^{\text {th }}$ century, social integration took 
place increasingly, via rising consumption opportunities and the demand of services, leisure industry and media. Consumption particularly gave people access to gratifications. This decisively influenced mass loyalty among people. Gratification through consumerism became important as the existing working relationship softened, the pattern of employment changed, unemployment increased considerably and as part-time positions and limitations in the length of employment were created. Although in politics and the public eye the idea of full employment was not given up for a long time, precarious working relationships increasingly arose, as well as longer interruptions between jobs, therefore recurring phases of unemployment in the career.

\section{Change in Work}

Today, 'work' is an enigmatic concept, which stretches far beyond the traditional gainful employment (freelance or employed) or wage work (dependent gainful employment). In the broadest sense, an activity can be considered work if it is conscious, purposeful, and useful, not primarily aiming toward relaxation or recreation. In this sense, work marks an activity that spends all one's energy, but it results in a feeling of pride to have completed, created or caused something.

Related to paid work, unpaid activities may also be considered work. According to work definition, the following activities belong to work: shopping for external sources of sustenance, gardening to sustain oneself, making repairs in the apartment or the house, neighbourhood assistance, honorary positions (working for nature conservation for example), care of ill and old people, education and care of children, housework etc.

Today, an extension of the work concept can be noticed. Following the social changes, the concept of work has shifted from physically exhausting work in agriculture (agrarian society) and industry (industrialized society) to service work (service economy) in the middle of the $20^{\text {th }}$ century and to symbolic work (knowledge society), at the end of the $20^{\text {th }}$ century.

Although the everyday use of the term 'work' has extended beyond gainful employment, activities that are not subjected to money and wages are also considered work. Paid work continues to be the paradigm for work. 
A higher value is generally attached to it, because it secures the basic material living conditions in form of an income. In this respect, a concept that describes work as a source of a wage or income is preferred today, too. What is new related to this concept, it is the position that a person's income does not have to be bound to work or capital, but each person has the right to an unconditional basic income to live securely and without fear, whether he works in a paid position or does not work at all. This unconditional basic income will be presented in the end of the essay.

\section{Working Not Just for Money}

Certain ideas are related to the term 'work'. Even though in principle, people are intrinsically motivated to be active, heteronymous activities like industrial work and paid labour require additional extrinsic motivation and control.

The objection that humans are lazy by nature and that it is necessary to motivate them to work by exercising control can be easily invalidated. Mentioning the widespread opinions about the motivation to work, it is obvious that they are based on an alienated conception of work. The conclusions cannot be applied to non-alienated work. Laziness is not the natural state of the person, but a reaction to the alienating conditions of life and work (Fromm 1955: 290).

Also, the motivation to work does not only depend on money or material incentives. Adding to this, there are not enough jobs for large parts in working population. Man is considered a creature that is naturally disposed to activity and personal development. It is an expression of pathology, if a person strives more for idleness than for activity.

In our society, the motivation to work is regarded as largely dependent on money and other material incentives, although this is neither the only motivation, nor the most distinguished. When a work activity rests on a high level of qualification and is characterized by independence and self-determination, material incentives play a subordinate role. The aspiration for money and power cannot replace a meaningful work activity. However, the majority of the workforce does work that is not very demanding. 'Dissatisfaction, apathy, boredom, lack of joy and happiness, a 
sense of futility and a vague feeling that life is meaningless, are the unavoidable results of this situation' (Fromm 1955: 295).

People, who do alienating work, are employed precariously or are out of work. They will base their motivation to work on wages and will tend to seek compensatory activities outside the working day.

Under certain circumstances, people are willing to be active and make an effort, even without material incentives. This is clearly the case in recreational sports, in hobbies and in honorary activities. Idleness would probably suggest a problem. Beings as active creatures would search for meaningful activities.

With respect to the motivation to work, Erich Fromm has referred to the pioneering work of Elton Mayo, who, as early as the 1930s, could prove that interest in the working process considerably increases both the motivation to work and the willingness to exert oneself:

'The very fact that unskilled women workers were drawn into the experiment of work productivity of which they were the subjects, the fact that they became interested and active participants in the experiment, resulted in increased productivity, and even their physical health improved' (Fromm 1966: 178).

Although such research has already existed for almost eighty years, its consequences for the organization of work have not been explored extensively enough. Apparently it takes a very long time for such knowledge about the possibility of self-empowerment in the work process to reach the people's hearts and minds.

Another conclusion to this point of view is that money is not the only or the most important incentive for work. People, who prefer working to idleness, choose this alternative, as work must demand the workers' strengths. Work should be socially or technically attractive and interesting to challenge and stimulate the workers.

To understand work better it is necessary to analyse the historical changes. In antiquity, work was negatively valued and was related to slaves. Contemporary societies are based on the tradition of a positive valuation of work. Especially in our consumer society, wages and incomes enable the participation in consumption. In the $21^{\text {st }}$ century, a new understanding of work, beyond gainful employment, will become generally accepted. 


\section{The Concept of Social Character}

Three perspectives can be found in Erich Fromm's work: the anthropological perspective, which focuses on the nature of man, the social perspective, focusing to socio-economic structure and social character, and the personal perspective, which focuses on each person's uniqueness and individuality. In the following section, the social character perspective is central.

Social character theories begin with Fromm's description of the authoritarian social character in the 1930s and his subsequent description of the marketing character in the 1940s. David Riesman adopted the concept of the social character from Erich Fromm and described three types of character, which he called the tradition-directed, inner-directed and otherdirected (Riesman, Glazer and Denney 1950). The concept of social character is suitable to grasp the changes in the character structure that have accompanied the social changes in the work structures and the structures in the social environment.

Erich Fromm describes the social character as socially significant, functionally character structure for the work process, which is typical to people in society, social class or reference group. He correspondingly defines the social character as "the nucleus of the character structure which is shared by most members of the same culture in contradistinction to the individual character in which people belonging to the same culture differ from each other. The concept of social character is not a statistical concept in the sense that it is simply the sum total of character traits to be found in the majority of people in a given culture" (Fromm 1955: 78).

In his work on social character, Fromm considers the social character a guarantor of social cohesion and integration. Fromm explains the appearance of a specific social character, with the consequences the character brings about. For example, the authoritarian character exists because it fits into the hierarchy of an authoritarian state and is obedient. The marketing character exists because it fulfils the expectations related to work and consumption. Character formation means internalizing social expectations and necessities, so that the social order is maintained. 
For functioning, a society requires certain character traits, including obedient submission. People exhibit exactly these character traits. So the authoritarian character admires strong authorities to whom he willingly submits, because he takes part in the authority's strength by identification. With his orderly thinking and his support of discipline and subordination, he is the ideal subject for these authorities. He also submits willingly to factory discipline and heteronymous orders.

While the authoritarian character was typical in the first half of the $20^{\text {th }}$ century, the marketing character was typical in the second one. In contrast to the authoritarian orientation, the marketing orientation is not about obedience and submission, but about the ability to market and selling oneself and one's abilities.

The marketing character follows predominantly the "anonymous" authority of public opinion, fashion, and convention. It is recognized as a person and his sense of belonging come from being exactly like all the others in his reference group. The readiness for consumption is an essential feature of this character type, which in its more "productive" varieties, can also be identified by flexibility, objectivity and fairness.

In continuation of Fromm's analytical social psychology, Rainer Funk described the postmodern character orientation, during the last few years (Funk 2005). This new character orientation corresponds to the changes in the way of life of social strata and classes, which today are also described by the model of social milieus. Consumption-oriented attitudes (maximum consumption, demonstrative consumption) and postmodern attitudes (experimental and hedonistic life with fun and diversion, life as a "project" with open and uncertain horizons) developed to traditional attitudes (disciplined, ordered life based on work, job security and social safety). The social character has changed and become more diversified. Social experiences specific to certain milieus, such as work (including precarious working conditions and unemployment) and consumption influence and form the social character. 


\section{Social Character and Education}

Societal influences are essentially transmitted to people through education and socialization processes. These processes can be described using the 'social character', which represents logical marks for education and socialization processes. Fromm has emphasized that the social character mediates between the socio-economic structure and the individual emotional structure:

'The socioeconomic structure of a society melds the social character of its members so that they wish to do what they have to do' (Fromm 1976: 133).

This formative process happens through education in the family, which essentially becomes the 'psychological agent of society' (Fromm 1941: 285). For Fromm, education must be understood 'in the context of the social structure, and particularly as one of the key mechanisms of transmission of social necessities into character traits' (Fromm 1949: 12). The function of education:

'... is to qualify the individual to function in the role he is to play later on in society; that is, to mold his character in such a way that it approximates the social character, that his desires coincide with the necessities of his social role' (Fromm 1941: 284).

It is always the social way of life - determined primarily by the socioeconomic base of society - that forms the individuals' personality A society's or classes' typical characteristics are transferred to the individual in the family, so that he is able to live in a particular social environment. If the individual is required to be nothing, but an anonymous worker, familial education must set the course and repress the child's spontaneous impulses:

'The suppression of spontaneous feelings, and thereby of the development of genuine individuality, starts very early, as a matter of fact with the earliest training of a child.' (Fromm 1941: 240-241).

The desired results lie in the fact that the person becomes predisposed to be a worker and unquestioningly follows workplace norms like punctuality, precision and obedience. 
Members of society must be shaped in accordance to the social requirements. This formation process happens within the social realm of the family, which functions as an 'agent of the society' and shapes children so that they correspond to the culturally-expected personality.

In family, but also in other institutions, like kindergarten and school, the typical characteristics of society and social class are transferred to individuals, so that they become capable of living in specific social milieus.

It is essential to find out what types of personality are desirable and necessary in a certain culture. We must identify the characteristic elements of industrial society. It is not possible to explain the social character by focusing on child-raising methods, because these methods work only 'as a mechanism of transmission'. Instead, we have carefully to consider what character traits and orientations are expected from working people to fulfil the expectations of the capitalistic mode of production (Fromm 1955: 82-83).

With the change of the work organization and qualification structure in modern industrial companies, the expectations of the workers have changed as well. The conventional authoritarian character structure has not been suitable basis for the economically efficient utilization of the workforce, since the middle of the $20^{\text {th }}$ century. A multi-qualified worker is increasingly in demand. His qualities include: flexibility, quick perception, decision-making ability, sense of responsibility, reflexive distance, but also social competence. These 'dispositions' are the result of education, which can instil confidence in a child's developing forces and stimulates it to its own activity. Fromm distinguished an education that promotes child's strength and one which restricts it. For Fromm, the best education strengthens the child's reason and self development, an education based on the absence of fear (Fromm 1936: 161-162).

The development of the social character since the 1970 shows the increased flexibility mentioned above, which, nevertheless, also has its price. People are available as workers and consumers. Rainer Funk's explanation of the postmodern social character captures precisely the identity dilemma of this new social character orientation. The person is now forced to make necessity a virtue. He achieves this by the help of virtual worlds and borrowed identities, which constitute a strong ego that ultimately makes itself unassailable in its weaknesses (Funk 2005). 


\section{Characteristics of Post-Industrial Societies}

In today's world, Western societies can be described as post-industrial societies (Bell 1973). The post-industrial society is a service economy and a knowledge one that is highly industrialized with economically efficient agricultural production. The term 'post-industrial' is chosen for the area which has the most employees. Today, this is the service economy, which has expanded into symbolic work. The percentage of people working in farming (the primary sector) has gone down from about 70 percent in 1850 to under 10 percent today in Western societies. Employment in industry (secondary sector) has gone from approximately 25 percent at the beginning of the 20th century, to just fewer than 20 percent today. Services (tertiary sector) have grown from 10 percent to over 60 percent.

In this article, I present the essential conditions and elements of today's post-industrial societies. I focus mainly on the society-specific valuation of the 'human being' as productive resource in the working process, but I also show the changes in the relevance of work and consumption, that have become visible in the last few decades.

As already mentioned, focus has increasingly shifted from gainful employment, to consumer activity. Obviously, the economy is determined by the practical constraint of tapping extensive new markets for producing goods. To this, Fromm says:

'If the overriding economic principle is that we produce more and more, the consumer must be prepared to want - that is, to consume - more and more.' (Fromm 1968: 37).

Seen in this way, the work and its wage are reduced in importance, to the opportunities for consumption it brings about. Consumption itself is an important element in integrating people socially, as long as they are not excluded, because of a shortage of purchasing power.

In order to create the subjective conditions essential for the organization of work, the production of socially-usable, functional work capital cannot initially happen without compulsion and a sense of 
obligation. These conditions include compliance with specific performance standards, which are based on punctuality, reliability and precision.

Through the formation of a specific social character, industrial society has been able to harness a significant extent of peoples' energies for work:

'The necessity for work, for punctuality and orderliness had to be transformed into an inner drive for these aims. This means that society had to produce a social character, in which these strivings were inherent.' (Fromm 1955: 80).

This drive to work is essentially produced by equalizing and compensating the efforts and abnegations, compulsions and suffering, during working hours. Existing social wealth creates the condition for gratifications which motivates the work.

The understanding of work is connected to material incentives for workers that degrade work merely to an instrument. Functionalized work puts the worker in a position to buy goods and services as a consumer, which then becomes the real reason for work.

In this process, money plays the essential mediating role between work and consumption. Since all work is paid with money, (the abstract form of work) it reduces objects to their quantitative value and regulates the exchange of objects of different qualities (Fromm 1955: 112).

On one hand, it must be a great and constantly renewing supply of goods and services based on this exchange of quality for quantity and viceversa. On the other hand, the working conditions create the need for these goods.

Though consumption was initially functionally necessary as compensation for the deprivation and reduction that workers suffered during work, consumption has gained more and more of its own meaning, relative to work. Functionalized work has become a need because it makes compensatory consumption possible. Thus, consumption becomes the real meaning of life.

Structurally, unemployment is connected to the transition from the industrialized society to the post-industrial service and knowledge society. Through rationalization and automation, workplaces have been lost. At the same time, the service sector developed next to the production of goods. Jean Fourastié called a service economy the arising type of society (Fourastié 176 
1954). With the increasing influx of scientific knowledge, into wide spans of production and administration, and through the exchange of science and technology, society changed toward a knowledge society. In the knowledge society, professional experience is increasingly replaced by current scientific knowledge, because of its obsolescence. Due to the immense increase of services and the accelerated exchange of knowledge and technology, industrialized society has become post-industrial.

For this society, the former occupational paradigm of a full-time job for an unlimited period is no longer authoritative and leading.

In connection with increasing globalization, the claims on workers have changed in the direction of increased mobility and flexibility. Moreover, hard physical labour has declined considerably and fallen in the background. In the same measure, qualified use of knowledge, the processing of information for specific uses, has increased. At the same time, a new culture of capitalism has risen, in which the access to experiences, services and better conditions has got more important than property (Rifkin 1995, 2000).

If, like Fromm, we define the work of the industrial worker 'as the performance of acts which cannot yet be performed by machines' (Fromm 1955: $180)$, then it is clear to see that this work is declining with the advances in microelectronics technology (Schaff and Friedrichs 1982; Gorz 1989, 1999).

In The Sane Society, Fromm summed up his description of work in contemporary society as follows:

Most people carry out jobs which have no beneficial effect on the development of their personal forces and special talents and skills. Unlike managers and members of highly qualified professions, workers sell their abilities to an employer who uses them for profit purposes. The purpose of working is reduced to making money for covering the costs of living and having little chance to satisfy the consumer greed. 'Dissatisfaction, apathy, boredom, lack of joy and happiness, a sense of futility and a vague feeling that life is meaningless, are the unavoidable results of this situation. This socially patterned syndrome of pathology may not be in the awareness of people; it may be covered by a frantic flight into escape activities, or by a craving for more money, power, prestige. But the weight of the latter motivations is so great only because the alienated person cannot help seeking for such compensations for 
his inner vacuity, not because these desires are the 'natural' or most important incentives for work.' (Fromm 1955: 295).

The development of productive forces has experienced a qualitative jump since the middle of this century, with the development of microelectronic technology. Increasingly, the intellectual abilities of the human being are supplemented or even replaced by automatically controlled machines:

'In the middle of the twentieth century we find an increasing tendency to employ automatically regulated machines which have their own 'brains', and which bring about a fundamental change in the whole process of production.' (Fromm 1955: 104).

The human work in production and in the service sector is decreasing (Schaff 1987: 24).

According to Adam Schaff, this process is connected with the socialpsychological problem that work must be replaced with an alternative that provides both a source of income and a 'sense of life'. On the one hand, people must be able to satisfy their material needs with an income to cover the cost of living. On the other hand, they need an activity which could compensate for the gradual disappearance of traditional human work, an activity to motivate human action and to form the basis for the satisfaction of non-material, mental needs.

The question is whether a meaningful alternative to conventional gainful employment can be developed, which could include a 'worthy and purposeful occupation for structurally unemployed persons, particularly for young people' (Schaff 1987: 145). Adam Schaff fears an increase of social pathologies among young people in the western world who are affected by structural unemployment. Preventative measures would have to be introduced before destructive branches of extremist groups can develop and exercise extreme force or organized terror in connection with drug addiction and alcoholism (Schaff 1987: 160-161).

A possible solution could be to come up with activities which simultaneously replace dwindling paid work and develop a new meaning of life. Adam Schaff refers to the fact that the meaning of human life was always connected with some activities, but these activities did not always 
correspond to our present definition of work as paid work or as its alternate forms (Schaff 1987: 143-144). Occupations and activities beyond wage work can take the place of work in the traditional sense.

These new forms of occupation must fulfil several conditions. They must be socially acceptable for people. They must serve as a source of income and consequently, material protection. They must form the foundation for satisfying everyday needs. They must offer prospects of social status regulation and social advancement, and they must be a source of joy in life.

'Meaning creating activities', socially approved, with social engagement that have only little in common with traditional paid work, could compensate for the loss of meaning, caused by structural unemployment, and beyond this, new communitarian structures in the community.

\section{The Future of Work and the Unconditional Basic Income}

Fromm's ideas of a new society are linked - like the Marxian vision of a humanistic socialism - to the idea of respect for the individual. The individual must be actively and responsibly involved in the interests of society. Furthermore 'the gap between our great intellectual achievement and our emotional and moral backwardness' is to be closed. We must overcome 'an empty technological concept of "progress"' as well as 'irrational contradictions' (Fromm 1960). The social surplus does not make humans innerly richer or freer.

Fromm introduces a number of practical suggestions that describes the future humanitarian, communitarian society, in concrete terms. In this society, the individual must be actively and responsibly involved in the interests of society. The author presents an array of suggestions and examples that clarify his conception. He then mentions the aim:

'(...) to create a work situation in which man gives his lifetime and energy to something which has meaning for him, in which he knows what he is doing, has an influence on what is being done, and feels united with, rather than separated from, his fellow man.' (Fromm 1955: 321). 
In order to achieve this aim, the break from centralized structures is necessary. Peoples' participation in a decentralized system embeds them in easily comprehensible structures, in which they can have an impact. Fromm suggests that the worker participate in management and decision-making by direct codetermination and self-responsibility.

His suggestions to humanize work do not aim to an increase of economic production; the goal not being greater satisfaction with work, but a completely changed structure of society, in which economic activities are subordinated to social life and human well-being (Fromm 1955: 326).

Fromm declares himself in favour of not changing isolated parts, but the whole of the social structure. The decisive feature in changing the social structure is that economic activity becomes a subordinate part of social life. Fromm criticizes that the economy has become independent with the development of capitalism. In other cultures, the economy is a part of society, but it has become the leading subsystem in our society. This development must be turned around. The economy must be subordinated to society and cannot continue to determine peoples' social situation and their everyday lives.

The spheres of human life must be tied into a comprehensive whole. Fromm says:

'It is the very evil of present-day culture that it separates and compartmentalizes the various spheres of living. The way to sanity lies in overcoming this split and in arriving at a new unification and integration within society and within the individual human being.' (Fromm 1955: 326).

The way to a sane society lies in overcoming this split. Social usefulness, not profit, should determine production. Fairness in distribution must be created in national economies and worldwide. Fromm wrote:

'Reduction of unnecessary consumption in the industrialized countries is a must if they want to help the non-industrialized countries, and they must want to help them, if they want peace.' (Fromm 1955: 333).

Fromm marks alternatives to post-industrial capitalism flatly with suggestions for 'sane consumption', for instance. When he promotes 
decentralized communitarian structures as an alternative, these structures are first related to working conditions. Communitarian ideas are to be leading principles of the entire way of life. A communally-structured society is marked by human relatedness and relationship security. In order to make this structurally possible, Fromm sees the necessity to unconditionally protect the individual as a member of the society with a guaranteed base income.

Erich Fromm had already formulated his suggestions for basic social protection in the 1950s. He pointed out that an income that guarantees a dignified human existence is necessary. This income may not be too low, however, so that it does not cut into personal development or the experience of life (Fromm 1955: 334-335). Therefore, there should not be a fixed amount for all. Rather, 'each according to his needs, each according to his abilities' (Karl Marx). But irrespective of how useful an individual is for society, he has an inalienable right, as a member of this society, to live in dignity.

Such an unconditional base income, which to Fromm is merely an extension of social security, allows the individual's right to refuse work without suffering hunger or social stigma, regardless of whether he or she has a job or not. Fromm pleads for a 'freedom of contract between employers and employees', which is not yet given 'in the present capitalist system', but would have liberating repercussions on all social arenas:

'But such a system would be not only the beginning of real freedom of contract between employers and employees; it would also enhance tremendously the sphere of freedom in interpersonal relationships between person and person in daily life.' (Fromm 1955: 337).

Individuals must be given priority, and must be understood not as things, but only as ends in themselves:

'Man's use by man must end, and economy must become the servant for the development of man.' (Fromm 1955: 361).

In 1966, Fromm concentrated almost exclusively on the psychological aspects of a guaranteed income and questioned about the effects, the risks and the human problems which accompany its introduction (Fromm 1966). Fromm considers it is essential that a guaranteed income to have the 
potential to significantly extend individual freedom. It creates freedom of fear, because the basic needs of the individual are socially secured and people no longer have to submit to unworthy working conditions to live a dignified life. A latent threat was connected with the traditional understanding of work that if someone refused work, he had no right to live. This threat did not only discipline people with respect to work behaviour, but also determined their attitudes and their way of thinking. Work, including alienating work, was regarded as the primary purpose of life.

Connected to the guaranteed income is the idea that in principle, each person has the right to live. Fromm evaluates 'this right to live, to have food, shelter, medical care, education, etc.', as 'an intrinsic human right that cannot be restricted by any condition, not even the one that he must be socially "useful"' (Fromm 1966: 176). The individual's right to live in dignity, as a member of society, does not depend on his motivation to work, but it is related to human dignity and to the right to freely choose the activity that guarantees effectiveness and personal development.

Substitute income without work such as an unemployment benefit lowers the recipient's self-esteem and reduces his opportunities of social participation. The freedom to choose between meaningless paid work and meaningful unpaid work is only partially possible. Because the predominant paradigm sees work as 'a means of getting money, not in itself as a meaningful human activity' (Fromm 1955: 180), people are brought to the paradoxical situation that they run after alienating work.

Even if the meaning of work is seen in compensation, one cannot overlook the fact that a person cannot base his or her self-esteem on the amount of his wage alone. Certainly, work is often done in order to secure basic survival, but further, work is a phenomenon of one's own strengths' improvement. Work can be related to need and necessity, but also to abundance and freedom. Work is bound to the 'realm of necessity'; however, in transition, it also creates the material and ideal values of the 'realm of freedom'. While alienating work can cause illness, meaningful, useful, demanding work stimulates individual strengths and is part of a sane and healthy way of life. 


\section{The Basic Income as the End of Unemployment}

Without dealing with details of the different positions and concepts, I sum up referring to the basic income is to be understood. The guaranteed basic income is a system of social security that should enable everybody to live without worries and social pressure in entire lifespan. Such a concept is discussed from different viewpoints, for instance, from a humanisticsocialist point of view or a neoliberal's one. Their interests are different and the intended modalities of realization differ considerably.

Relative to the current control and sanction-oriented basic social security, the basic income should be regarded as an absolute and inalienable right. It is combining with work income and is given to individuals, not households.

The basic income is a foundation from which everyone, without any obligation to work activity, controls sufficient assets to allow existence and participation in social life. This basic income is completely unconditional. Regardless of whether a person makes a substantial contribution to the community or not, everyone has the right to a dignified existence.

The advantage of such a basic income lies in the fact that people can shape their lives in freedom, without fear or worry. It would also bring about the end of unemployment pay, because unemployment would no longer be a criterion for receiving benefits. Only the fact that somebody is human and the member of a society would be determinative. A further advantage of a basic income to secure basic existence is that it does not have to cost more than the current need-based social aid.

The basic income encourages people to take up non-professional activities (volunteer work, honorary office, personal development, activities in art and philosophy). This would, in turn, affect community life and would increase the quality of life.

The basic income can prevent poverty, particularly for families and children. Single parents often have difficulties in finding jobs, especially when there is a shortage of childcare facilities. Frequently, this lack of support in everyday life also causes health problems arose from the mere stress of daily planning.

A guaranteed minimum income can maximize the freedom of the individual, increase self-respect and reduce social exclusion and shame. It 
leads to more social equity and equal opportunities, and makes it easier to arrange life with or without a job. People can actively and formatively approach the challenges of their own lives and of today's society.

In summary: the basic income is a protection of human dignity, a contribution to the prevention of poverty - of child poverty as well - a fulfilment of everyday life in the sense of providing freedom from cares and fears. Life organization becomes possible on such a safe foundation. Peoples' more noble sides can come to light such as social consciousness, compassion and emotional intelligence, instead of always having to limit damage to one's own life, particularly at work. Unemployment would no longer be a risk and would stop being a threatening fact.

\section{Does the Basic Income Promote Human Laziness?}

The formation of an industrial social character is related to discipline and subordination. The man corresponding to this character structure firstly assumes that every person had to earn the right to exist through obedience, diligence and self-discipline. This conception of man is, however, merely an answer to the social formation of man, required for production and the way of life at that time. How people can develop under conditions of freedom, it is obviously not answered by this perspective. As long as man is regarded as bad, selfish, jealous and antisocial, one cannot believe him capable of circumspection, responsibility and initiative. It is needed to control and discipline him. The basic income breaks with this pessimistic conception of man and its self-fulfilling prophecy and presupposes man to be a relational and responsible being.

Under the conditions of a deficit economy, the fundamental moral position of unconditional recognition of human dignity could hardly spread out. Contemporary consciousness of the development of industrial societies in rich, 'affluent societies' does not carry sufficient weight, either.

For many people, the idea of the guaranteed basic income is too strange for them to accept it. This is related to social experiences that convey a certain conception of man. If people are lazy by nature, a guaranteed income could impair their willingness to work and lead them to prefer idleness to work. 
Critics have pointed out that the effect of a basic income may cause people to give up gainful employment altogether. Everybody has the duty to increase society's well-being by working within the scope of his or her possibilities and abilities. A basic income that is too high could result in idleness and egoism. The danger is of institutionalizing a culture of laziness in which the value of work is questioned. Corresponding arguments against the basic income are based on a negative conception of man (laziness, abuse of public assistance, living at others' expense).

It cannot be denied that under specific pathological conditions, people can abuse the basic income to sit around and do nothing. The more unproductive the character structure of a person has become and the more limiting, oppressive and hurtful his life conditions have been, the lower is the probability that a basic income will be useful in the sense of selfactivation for personal development and socially useful activities. These conditions are nevertheless connected to social pathologies, which themselves find an expression in psychosocial restrictions, defects and neuroses. On the other hand, bondage to authority and consumption are to be questioned as forms of the 'pathology of normalcy' (Fromm 1955: 12-21).

Today's overconsumption with its avarice for variety, diversion and amusement can hardly be interpreted as a sign of psychosocial health and well-being. If one wants to use the term laziness, then one should differentiate between a reactive laziness, which is a psychopathological condition characterized by tormenting boredom (and indicates social pathology) and creative laziness, which is connected to recreation and productivity. Fromm makes unequivocally clear that the ideal of laziness is itself a result of pathological conditions:

'The alienated and profoundly unsatisfactory character of work results in two reactions: one, the ideal of complete laziness; the other a deep-seated, though often unconscious hostility toward work and everything and everybody connected with it.' (Fromm 1955: 182).

Fromm sees 'the widespread longing for the state of complete laziness and passivity' as a pathological symptom, not at all as a trait anchored in human nature (Fromm 1955: 182). He considers that current views on work motivation are based on the concept of alienated work; therefore, their 
conclusions do not apply to non-alienated, attractive work. If people show a longing for laziness and for doing nothing, this is merely a symptom of the meaningless and alienated conditions of life (Fromm 1955: 290).

The social change in the transition to the $21^{\text {st }}$ century has made it clear that the new socio-political models must be developed into work and income.

\section{References:}

Bell, Daniel. 1973. The Coming of Post-Industrial Society. New York: Basic Books.

Fourastié, Jean. 1954. Die große Hoffnung des Zwanzigsten Jahrhunderts. Köln: Bund-Verlag.

Fromm, Erich. 1976. To Have or to Be? New York: Harper and Row Publishers.

Fromm, Erich. 1968. The Revolution of Hope. Toward a Humanized Technology. New York: Harper and Row Publishers.

Fromm, Erich. 1966. The Psychological Aspects of the Guaranteed Income. In The Guaranteed Income. Next Step in Economic Evolution? ed. Robert Theobald, 175-184. New York: Doubleday and Co.

Fromm, Erich. 1961. Marx's Concept of Man. With a translation from Marx's Economic and Philosophical Manuscripts by T. B. Bottomore. New York: Frederick Ungar Publishing Co.

Fromm, Erich. 1960. Let Man Prevail. A Socialist Manifesto and Program. New York: The Call Association.

Fromm, Erich. 1955. The Sane Society. New York: Holt, Rinehart and Winston. Fromm, Erich. 1949. Psychoanalytic Characterology and Its Application to the Understanding of Culture. In Culture and Personality, eds. S. Stansfeld Sargent and Marian W. Smith, 1-12. New York: Viking Press.

Fromm, Erich. 1941. Escape from Freedom. New York: Henry Holt and Company.

Fromm, Erich. 1936. Studien über Autorität und Familie. Sozialpsychologischer Teil. In Erich Fromm Gesamtausgabe in zwölf Bänden, ed. Rainer Funk, 1999. Vol. I, 139-187. München: Deutsche Verlags-Anstalt and Deutscher Taschenbuch Verlag.

Funk, Rainer. 2005. Ich und Wir. Psychoanalyse des modernen Menschen. München: Deutscher Taschenbuch Verlag.

Gorz, André. 1999. Reclaiming Work. Beyond the Wage-Based Society. Cambridge: Polity Press; Malden: Blackwell Publishers Inc.

Gorz, André. 1989. Critique of Economic Reason. London; New York: Verso. 
Riesman, David, Nathan Glazer and Reuel Denney. 1950. The Lonely Crowd. A Study of the Changing American Character. New Haven: Yale University Press.

Rifkin, Jeremy. 2000, The Age of Access. The New Culture of Hypercapitalism, Where All of Life is a Paid-For Experience. New York: Putnam Publishing Group.

Rifkin, Jeremy. 1995, The End of Work. The Decline of the Global Labor Force and the Dawn of the Post-Market Era. New York: Putnam Publishing Group.

Schaff, Adam. 1987. Wohin führt der Weg? Überleben in der Informationsgesellschaft. München: Goldmann.

Schaff, Adam and Günter Friedrichs. 1982. Microelectronics and Society. For better or for worse. A Report to the Club of Rome. Oxford; New York: Pergamon Press.

Sennett, Richard. 1998. The Corrosion of Character. The Personal Consequences of Work In the New Capitalism. New York: Norton. 